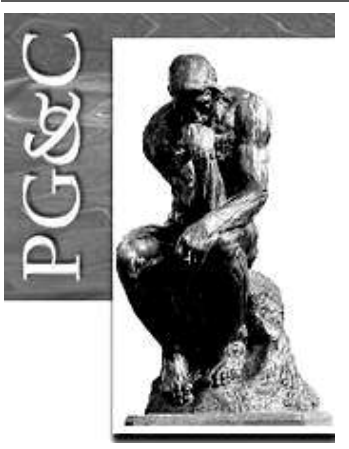

\title{
GESTÃO DO CONHECIMENTO NAS ORGANIZAÇÕES: UMA APRENDIZAGEM EM REDE COLABORATIVA
}

\author{
Katia Costa de Menezes \\ Especialista em Gestão do Conhecimento e Inteligência Empresarial pela \\ Universidade Federal do Rio de Janeiro. \\ E-mail: katia.costa65@gmail.com \\ Juliana Johann \\ Mestre em Relações Internacionais pela Universidade de Brasília, Brasil. \\ E-mail: juliana_johann@yahoo.com \\ Patrícia Passeri Valentim \\ Especialista em Gestão do Conhecimento e Inteligência Empresarial pela \\ Universidade Federal do Rio de Janeiro, Brasil. \\ E-mail: patpvalentim@gmail.com \\ Patrícia Scott \\ Especialista em Gestão do Conhecimento e Inteligência Empresarial pela \\ Universidade Federal do Rio de Janeiro. \\ E-mail: patiscott@hotmail.com
}

\begin{abstract}
Resumo
Este estudo pretende contribuir para o desenvolvimento da Gestão do Conhecimento (GC) em organizações de natureza hipertexto, onde o conhecimento é gerado em diferentes contextos interconectados e as estruturas burocráticas convivem com grupos de projetos desenvolvedores de novas soluções. Primeiramente, o estudo preocupou-se em definir o que é Gestão do Conhecimento e a forma como se comportam três tipos de organização (top down, botton up e middle-up-down) na criação do conhecimento. Em seguida, as características do modelo middle-up-down, também conhecido como hipertexto, serviram de base para a condução de entrevistas semiestruturadas, de acordo com a metodologia Investigação Apreciativa, com gestores envolvidos em projetos relacionados à GC em três organizações do setor industrial. O resultado mostrou que as empresas apresentam diferentes níveis de maturidade para implantação da Gestão do Conhecimento e quais áreaschave são propulsoras de GC nas organizações (Comunicação, Tecnologia da Informação, Projetos e Recursos Humanos). Essa análise também revelou as práticas de gestão do conhecimento que podem ser utilizadas para compartilhar, proteger, criar e organizar conhecimento. Por fim, o levantamento deu origem à ideia de desenvolver uma plataforma batizada de Colabore, para promover a troca e o aprendizado em rede sobre o assunto, haja vista que o diferencial competitivo das empresas na sociedade do conhecimento está na capacidade de aprendizagem de seus colaboradores, na geração de conhecimento, que aumenta exponencialmente a inteligência coletiva das organizações, possibilitando a inovação de produtos e serviços.
\end{abstract}

Palavras-chave: Gestão do conhecimento. Colaboração em rede. Aprendizagem organizacional. 


\title{
KNOWLEDGE MANAGEMENT IN ORGANIZATIONS: A COLLABORATIVE NETWORK LEARNING
}

\begin{abstract}
This study aims to contribute to the advancement of Knowledge Management (KM) in the organizations, especially those of a hypertext nature where knowledge is produced in intersected contexts, and where bureaucratic structures coexist with project groups promoting new solutions. The study firstly dealt with defining knowledge management itself and how the three kinds of organizations (top down, bottom up and middle-up-down) operate when creating knowledge. The middle-up-down model, also known as hypertext, was chosen as our study focus and the survey delved into its defining characteristics. This article carried out semi-structured interviews with representatives from GC related projects in three organizations within the industrial sector, based on the Appreciative Inquiry methodology. The results have shown that these companies have attained different maturity levels in the application of Knowledge Management and also confirmed the driving areas of KM in organizations (Communication, Information Technology, Projects and Human Resources). Moreover, this analysis identifies the knowledge management practices that may be applied to share, protect, create and organize knowledge. This survey led to the idea of developing a platform called Colabore ('Collaborate'), which seeks to promote exchange and network learning related to this subject, bearing in mind that the competitive advantage of companies in our knowledge society is based upon the learning abilities of its employees and on the creation of knowledge, which increases the collective intelligence of organizations exponentially, enabling the conception of innovative products and services.
\end{abstract}

Keywords: Knowledge management. Network collaboration. Organizational learning.

\section{INTRODUÇÃO}

Este estudo objetiva contribuir para a implantação ou o aperfeiçoamento da Gestão do Conhecimento $(\mathrm{GC})$ em organizações hipertexto, ou seja, empresas na qual o conhecimento é gerado em diferentes contextos interconectados, de natureza híbrida, onde estruturas burocráticas convivem com grupos de projetos desenvolvedores de novas ideias e projetos. Como integrar esses contextos, quais as áreas-chave capazes de movimentar a espiral do conhecimento nessas organizações?

Para aprofundar o trabalho, foram realizadas entrevistas semiestruturadas (conversa aprofundada sobre um assunto por meio de um guia de perguntas), baseadas na metodologia Investigação Apreciativa (Appreciative Inquiry) ${ }^{1}$, com representantes da área de Gestão do Conhecimento em três organizações hipertexto, que preferiram manter o anonimato para responderem, sem restrições, às questões abordadas.

Apesar de serem empresas de natureza distintas, elas reconhecem a importância da GC e vêm aprimorando sua gestão ao longo do tempo. Primeiramente, foi descrito como funciona a GC nessas organizações, avaliando o grau de maturidade delas (nível de prontidão). Compreendeu-se, também, a governança em conformidade com sua cultura organizacional, visão, missão e valores, além de terem sido identificadas as habilidades e competências essenciais. Para completar o quadro, foram realizadas análises SWOT (FOFA), revelando as forças, fragilidades, oportunidades e ameaças de áreas críticas que facilitam a GC nas empresas. Esse levantamento gerou um mapa inicial com as melhores práticas organizacionais de GC.

\footnotetext{
${ }^{1}$ A metodologia Appreciative Inquiry (em português, Investigação Apreciativa) aborda o que funciona bem na organização e é utilizada para compreender as capacidades e recursos organizacionais, visando à promoção de mudanças positivas. Mais detalhes na seção 2.2 .
}

Perspectivas em Gestão \& Conhecimento, João Pessoa, v. 7, Número Especial, p. 145-159, mar. 2017. 
Na sequência, são apresentados o referencial teórico e a pesquisa de campo - Gestão do Conhecimento nas Organizações Hipertexto. Nessa seção, o processo de GC vem embasado pela visão de três profissionais envolvidos em suas respectivas empresas, além dos resultados da análise SWOT, comparando as similaridades, que reforçam a hipótese inicial desse estudo: a existência de áreas-chave capazes de facilitar e impulsionar o sucesso da GC nas empresas.

O resultado serviu de base para a criação de um protótipo de plataforma transmídia, uma Rede Colaborativa de GC, batizada de Colabore -, cujo objetivo é aprofundar as questões tratadas neste artigo em um ambiente de aprendizagem colaborativo, no qual reúna interessados no assunto e promova debates e interações sobre GC nas organizações, incentivando aprimoramentos e melhorias no compartilhamento de práticas de gestão de conhecimento nas empresas.

\section{DESENVOLVIMENTO}

\subsection{Referencial Teórico}

As organizações modernas vêm sofrendo os impactos da sociedade do conhecimento, na qual o conhecimento é o principal fator de produção do século XXI e são afetadas por um grande volume de informações advindas de diversos meios, contrapondo-se à escassez, que prevalecia na sociedade industrial. O novo contexto instiga as organizações a refletirem as estratégias que devem ser adotadas para continuar sobrevivendo com sucesso no mundo competitivo. Atualmente, as novas formas de colaboração em rede sugerem que as organizações possam obter vantagens competitivas por meio de uma abordagem mais autoorganizada com a formação de equipes multidisciplinares, caracterizada por processos horizontais colaborativos nas empresas, que cruzam as fronteiras das áreas funcionais.

Para Katz et al. (2000), trabalhar em rede é um processo que consiste em organizar e manter a colaboração de forma eficiente. Portanto, deve ser alvo de muita atenção, com o objetivo de acessar ideias, tecnologias e compartilhar informações, experiências, conhecimentos técnicos e negócios entre organizações, institutos ou centros de pesquisa tecnológica e universidades. Segundo os autores, a base do trabalho em rede depende mais da confiança entre os "sócios" do que da firmação de contratos legais. Também ressaltam que o trabalho em equipe está relacionado com os modos de explorar a base de conhecimento da organização e de se desenvolver estrategicamente como uma "organização que aprende".

No entanto, para capitalizar conhecimento no contexto de sua criação, validação, apresentação e aplicação nas organizações é necessária a interação entre tecnologia, técnicas e pessoas, pois a ação conjunta, associada à criação de um ambiente, como "aprendizagem por fazer", permite que uma organização gerencie efetivamente seu conhecimento e crie condições para sustentar suas vantagens competitivas (ROSSETTI et al., 2007).

Do ponto de vista operacional, pode-se dizer que a gestão do conhecimento consiste em combinar o saber (explícito) e o saber fazer (tácito) nos processos e nos produtos da organização para a criação de valor. Por isso, é preciso combinar as competências individuais e o conhecimento, implantar uma cultura de compartilhamento de boas práticas na empresa, ampliar as redes de relacionamento, valorizar os ativos intelectuais e aumentar a sua capacidade de uso em cada contexto. Esses são os quatro capitais do conhecimento: relacionamento, humano, estrutural e ambiental.

Para vários autores, a gestão do conhecimento envolve o gerenciamento de ativos intangíveis de diferentes naturezas: pessoas, conhecimentos tácitos, explícitos, organizacionais, estruturais e de redes. Portanto, a gestão do conhecimento pode ser definida como a capacidade de lidar de forma criativa com as diferentes dimensões do conhecimento.

Perspectivas em Gestão \& Conhecimento, João Pessoa, v. 7, Número Especial, p. 145-159, mar. 2017. 


\subsubsection{Tipos de Organização}

Nonaka e Takeuchi (1997) mostram como se comportam três tipos de organização na criação do conhecimento. No modelo top-down (de cima para baixo), a organização é vista como uma pirâmide (modelo clássico da Administração), na qual os dados e as informações são filtrados à medida que sobem os degraus da hierarquia. Por outro lado, os executivos criam planos que fazem o caminho contrário, descendo até os níveis mais elementares por meio de ordens e instruções. Nesse esquema, é dado mais importância ao conhecimento criado na alta cúpula e os processos de conversão do conhecimento mais desenvolvidos são a combinação e a internalização, ou seja, trabalha-se mais com o conhecimento explícito.

No modelo oposto, bottom-up, a hierarquia e a divisão do trabalho dão mais espaço para autonomia, ou seja, os funcionários da linha de frente têm mais liberdade no processo de criação e controle do conhecimento, muitas vezes por meio de equipes de projetos e rede informal. A conversão desse conhecimento tácito é parcial e se realiza por socialização/externalização. A alta gerência exerce o papel de patrocinadora e/ou mentora, e a de nível médio atua como empreendedora.

Enquanto no primeiro tipo de organização descrito - top down - o armazenamento do conhecimento localiza-se em banco de dados computadorizado e manuais, no modelo bottomup o conhecimento fica armazenado no próprio indivíduo.

A união desses dois modelos faz surgir o terceiro: middle-up-down, cujo agente de criação do conhecimento é formado por equipes com gerentes de nível médio, como engenheiros do conhecimento exercendo o papel de liderança. Para o presente estudo, vamos aprofundar as características desse tipo de organização, também conhecida como organização hipertexto.

\subsubsection{A Organização Hipertexto}

Quando o conhecimento se revela por meio de diferentes contextos interconectados, a organização é classificada como hipertexto. Segundo Nonaka e Takeuchi (apud NORTH, 2010), ela é uma constituição híbrida, onde coexistem elementos de uma organização tipicamente burocrática (sistema de negócios em que se executam as ações operativas) e grupos de projetos para desenvolvimento de novos produtos e serviços, além de possuir uma base de conhecimentos, constituída por múltiplos saberes transmitidos por oficinas, seminários, informes etc., que fica à disposição de todos os integrantes da empresa.

[...] esse tipo de organização facilita o intercâmbio de conhecimento tácito entre especialistas de distintas áreas da empresa, gerando o conhecimento explícito pertinente. Desta combinação, resulta a justaposição da capacidade criativa adhocrática e a eficiência manifestada implicitamente na estabilidade burocrática (NORTH, 2010, p. 91).

O autor exemplifica o funcionamento da organização hipertexto como um ciclo dinâmico que atravessa três níveis: (1) sistema de negócios; (2) equipe de projeto; e (3) base do conhecimento. O primeiro nível - sistema de negócios - representa a estrutura hierárquica/burocrática. Em formato de pirâmide, é nesse nível que os colaboradores desempenham as atividades operacionais, que fazem parte da rotina da organização. No segundo nível - equipe de projeto - encontra-se a força-tarefa, formada por pessoas provenientes de diversas áreas do sistema de negócio com o objetivo de trabalharem, exclusivamente, no desenvolvimento de produtos e soluções, ou seja, na criação de conhecimento, adquirindo novas capacidades.

Perspectivas em Gestão \& Conhecimento, João Pessoa, v. 7, Número Especial, p. 145-159, mar. 2017. 
Abaixo, desses dois níveis, está a base de conhecimento. Apesar de não poder ser identificada como uma entidade física ou concreta, ela existe incorporada à visão, à cultura, aos processos e à tecnologia da organização. Perpassa os outros dois níveis e cada uma das pessoas da organização, pois armazena tanto o conhecimento criado na hierarquia quanto aquele criado na força-tarefa. Dessa forma, o conhecimento é recontextualizado e recategorizado em todos os níveis.

Figura 1 - A Organização Hipertexto

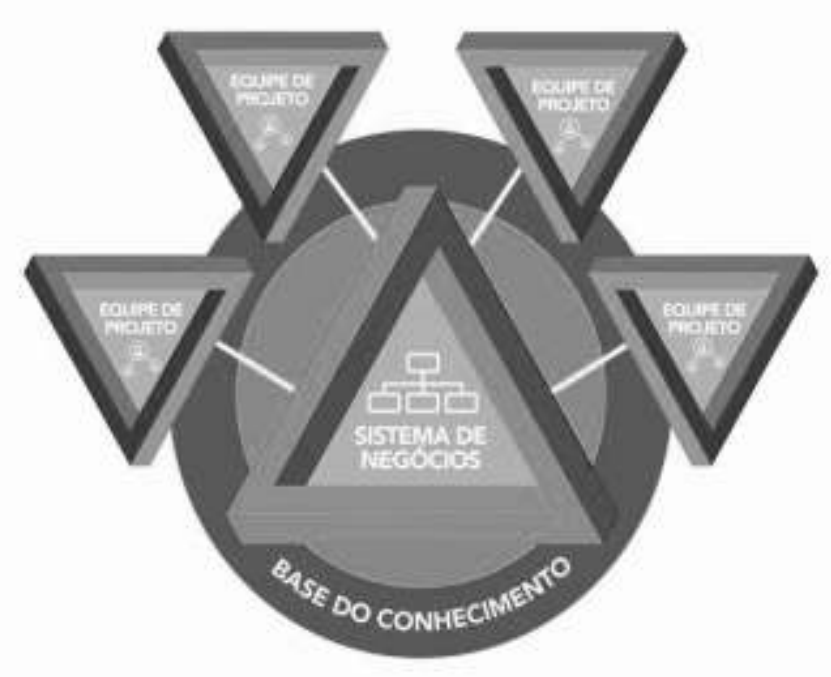

Fonte: Autoria própria

O processo concluído pelos resultados dos conhecimentos é um circuito dinâmico espontâneo, que leva em conta a sinergia dos três níveis. Quando o projeto é finalizado, as pessoas [da equipe de projetos] se deslocam até o nível base de conhecimentos, onde transmitem os saberes adquiridos no projeto mediante seminários, oficinas, informes, ou alimentando com dados os sistemas internos de informação da empresa (NORTH, 2010, p. 93).

Portanto, o modelo hipertexto eleva a capacidade estratégica da organização da empresa, ao permitir que novos conhecimentos sejam adquiridos de forma contínua em um procedimento cíclico de aproveitamento criativo.

Nesse contexto, o papel das plataformas tecnológicas é fundamental para a sobrevivência das empresas na sociedade do conhecimento. Elas servem de apoio para o registro de ações e processos, e facilitam a troca de ideias entre as pessoas. No entanto, não definem por si só as conexões inesperadas, ou seja, o surgimento de links (fortes e fracos) nos relacionamentos, que impulsionam novas possibilidades de ação e reação dentro de uma organização. Elas oferecem o suporte para as interações, que diferem na quantidade e qualidade, de acordo com a visão, missão, valores e objetivos estratégicos da empresa. 


\subsection{Gestão do Conhecimento nas Organizações Hipertexto}

Esta seção apresenta a visão de três profissionais que trabalham com gestão do conhecimento em organizações, de configuração hipertexto do setor industrial, classificadas de acordo com os critérios de porte de empresa adotados pelo Banco Nacional de Desenvolvimento Econômico e Social (BNDES) ${ }^{2}$.

Para isso, foi elaborado um roteiro com perguntas semiestruturadas, baseado na metodologia Appreciative Inquiry que busca, essencialmente, descrever as características e problemas, revelar análises de contexto e mudança, além de encorajar os entrevistados a propor possíveis soluções em face dos fatos revelados nas respostas às perguntas apreciativas.

De acordo com Judy e Hammond (2006, p. 1), no artigo An Introduction to Appreciative Inquiry:

Appreciative Inquiry encourages groups to inquire about, learn from, and build on what is working when they are at their best, rather than focusing on what is gone wrong and fixing problems. By using it to understand their capabilities and resources, organizations bring about and sustain positive change.

As entrevistas basearam-se em um roteiro dividido em duas partes, na qual a primeira é direcionada ao entrevistado e a segunda à área de GC, na qual o entrevistado atua. A fim de atender ao desafio do trabalho, os profissionais preferiram se manter anônimos. Eles contribuíram com seus pontos de vista e opiniões sobre as questões de foco, observação, análise e feeling (sentimento), além de responderem questões relativas à visão, percepção de mudança em seus ambientes organizacionais e as práticas de GC, no período de maio a julho de 2015. Por meio de análise SWOT (forças, fraquezas, oportunidades e ameaças), foram identificadas as similaridades, diferenças e o grau de maturidade dessas organizações.

\subsubsection{Gestão do Conhecimento na Organização A}

Classificada como média-grande empresa, a organização A é bastante competitiva no cenário internacional e possui mais de cem mil empregados distribuídos pelo mundo.

Nela, a GC está sob a responsabilidade da área de Gestão de Projetos de Investimentos (GPI), desde 2010. Anteriormente, houve uma iniciativa de desenvolvê-la na área de Recursos Humanos (RH), mas devido à reestruturação interna e "a crença de não estar agregando valor", a GC recomeçou do zero na área de GPI, ou seja, sem contar com as lições aprendidas e a transferência do conhecimento organizada pela área de $\mathrm{RH}$.

Nessa empresa, o alcance da gestão do conhecimento é limitado, destina-se à própria área que é estratégica, focada no core business e cuja Diretoria (de Projetos) está diretamente ligada ao Chief Executive Officer (CEO). Apesar de os três funcionários do setor desempenharem as mesmas funções, eles possuem competências diversas e seguem os preceitos do guia Project Management Body of Knowledge (PMBOK) - um conjunto de boas práticas na gestão de projetos elencadas por profissionais da área e organizado pelo Project Management Institute (Instituto de Gerenciamento de Projetos).

\footnotetext{
${ }^{2}$ De acordo com a classificação do BNDES, caracteriza-se como média empresa, aquela com receita operacional bruta anual maior que R\$ 16 milhões e menor ou igual a R\$ 90 milhões; a média-grande empresa possui receita maior que R\$ 90 milhões e menor ou igual a $R \$ 300$ milhões; e grande empresa, maior que $R \$ 300$ milhões (BANCO NACIONAL DE DESENVOLVIMENTO ECONÔMICO E SOCIAL, 2011).
} 
O entrevistado é formado em Engenharia Elétrica com MBA em Gestão Empresarial e seus colegas também têm formação em Engenharia, com especializações distintas. O que o levou a trabalhar em GC foi a necessidade da área de Projetos, onde já atuava, em capturar e organizar conhecimentos críticos e disseminá-los nos projetos existentes de acordo com os critérios de mapeamento das entregas e dos objetivos a serem alcançados em cada projeto.

O principal entrave para a implantação da GC na empresa é a dificuldade de "transmitir confiança às pessoas para que elas estejam mais abertas ao compartilhamento de suas experiências". Os funcionários percebem o trabalho de GC com "um pouco de desconfiança" e com receio de que o conhecimento capturado não será compartilhado contra eles.

Entre as principais ações de GC destacam-se: portal de compartilhamento, comunidades de prática, lições aprendidas, páginas amarelas ou lista de experts, treinamentos e registro de boas práticas. Essas funcionalidades estão integradas por meio da plataforma colaborativa, SharePoint da Microsoft, na qual é possível gerir e disponibilizar portais, intranet e extranet, websites, gestão documental e arquivos, espaços colaborativos, ferramentas sociais, pesquisa empresarial, Business Intelligence (BI), integração de processos e sistemas, e automatização de fluxos de trabalho.

Também são realizados eventos presenciais, seminários, workshops de coleta e disseminação de lições aprendidas. Os índices quantitativos contribuem para aferir a eficácia do setor: o percentual de participação nas comunidades de práticas e o número de lições aprendidas submetidas e reutilizadas, a quantidade de posts publicados e as estatísticas de acessos. No entanto, não existem indicadores qualitativos de mensuração do trabalho desenvolvido e nem a garantia da replicação de boas práticas e de lições aprendidas.

São promovidas, ainda, ações de incentivo para elevar a participação dos empregados nas comunidades de práticas e, mensalmente, há o reconhecimento dos empregados que mais utilizaram as ferramentas de compartilhamento. Como resultado, cresceu em cerca de $30 \%$ a quantidade de acessos por pessoa em um ano.

Segundo o entrevistado, é imprescindível um plano de comunicação interna para encorajar os funcionários a usarem mais as ferramentas de GC, sensibilizando-os para que conheçam as ideias e práticas de seus próprios colegas. "É necessário comunicar mais de forma criativa por meio de lideranças sensibilizadas sobre a importância de GC".

Entretanto, não é possível afirmar que a GC vem gerando inovação nos processos. "Quanto mais pessoas compartilharem suas experiências e conhecimentos mais eficientes serão, sem precisar reinventar cada nova tarefa em sua área", acredita o entrevistado.

As áreas críticas para a implantação de GC, citadas pelo profissional, foram Tecnologia da Informação, Recursos Humanos, Projetos e Marketing e Comunicação.

\subsubsection{Gestão do Conhecimento na Organização B}

A organização $B$ é uma prestadora de serviços na área da indústria sem fins lucrativos e, de acordo com os critérios do BNDES, é considerada uma grande empresa. O projeto de implantação da Gestão do Conhecimento nesta organização começou em 2012 e contou, inicialmente, com o patrocínio da Diretoria de Inovação na criação de uma área autônoma de GC para incentivar uma mudança cultural em sintonia com os objetivos estratégicos da Instituição.

O primeiro desafio foi a escolha da plataforma tecnológica para o desenvolvimento de uma Intranet de via dupla, ou seja, um espaço virtual que ultrapassasse a barreira de ser apenas um repositório de informações, com funcionalidades de compartilhamento das práticas organizacionais e de rede social colaborativa, integrando os empregados de norte a sul do país.

Perspectivas em Gestão \& Conhecimento, João Pessoa, v. 7, Número Especial, p. 145-159, mar. 2017. 
Para isso, os três integrantes da equipe de GC estudaram os impactos que as tecnologias sociais estavam trazendo para as organizações e realizaram benchmarking em empresas fora do país com alto nível de maturidade em GC, como a Shell e Philips. A entrevistada, que é formada em Economia com pós-graduação em Marketing, conta que foi um período de muita motivação profissional e aprendizado. Com o apoio da área de Tecnologia da Informação, escolheram a plataforma colaborativa SharePoint da Microsoft 2010, que permite a customização de várias funcionalidades, garantindo assim a exclusividade da ferramenta para aquela organização.

No final de 2013, a Intranet, finalmente, entrou em funcionamento na empresa por meio de uma extensa campanha interna, palestras e treinamentos. Desde então, as ações de divulgação e incentivos da utilização da plataforma passaram a ocorrer de forma sistemática. Todos os e-mails marketing enviados (Destaques do Dia) levaram o usuário a acompanhar as notícias e novidades na empresa. Os demais veículos da empresa, como a TV corporativa, também passaram a explicar, constantemente, as funcionalidades do portal. As lideranças foram capacitadas, por meio da metodologia Action Learning, com o objetivo de sensibilizarem suas equipes sobre a importância do uso da nova ferramenta.

A adesão alcançou $80 \%$ dos 7 mil usuários e, em julho de 2015, possuía 6 mil perfis criados e mais de 600 sites departamentais. A Intranet está dividida em três ambientes: o ambiente individual é o local onde se encontram os registros pessoais dos funcionários, currículo, competências, histórico na empresa, uploads de documentos pessoais etc; o ambiente de área é o espaço de criação dos grupos transversais que necessitam de recursos audiovisuais, como os de execução de projetos, compartilhamento de ideias, fóruns de discussões, comunidades de práticas, entre outros; e o ambiente corporativo hospeda o conteúdo informativo da "Intranet antiga", as notícias dos sites departamentais por meio de notícias online, vídeos e áudios.

Apesar de a gestão do conhecimento estar centrada no uso da plataforma, outros projetos de GC impulsionam a espiral do conhecimento na organização: knowledge café (onde as pessoas encontram-se para discussão de um determinado tema), benchmarking, ações de storytelling, encontros presenciais de lições aprendidas e um projeto de memória corporativa.

$\mathrm{Na}$ época desta entrevista, era possível medir a quantidade de acessos e compartilhamentos no portal, mas não se podia aferir a qualidade dos compartilhamentos, porque os indicadores e métricas qualitativas ainda estavam em fase de elaboração.

De acordo com a entrevistada, o maior desafio é a mudança de cultura dos funcionários: "Eles precisam ter em mente que cada um é responsável pela gestão de seu próprio conhecimento. Cabe à área de Gestão do Conhecimento oferecer ferramentas e métodos que auxiliem no compartilhamento e na disseminação de ideias. Portanto, um projeto de GC precisa, necessariamente, do engajamento de cada colaborador da organização."

Entre os exemplos de sucesso da implantação do portal, a profissional citou o de uma unidade que necessitava de um atestado técnico para participar de uma concorrência. Por meio da pesquisa dos perfis na Intranet, descobriu-se em que setor havia um profissional com a devida qualificação e, por fim, conseguiram vencer a concorrência e concretizar o negócio.

No período de quase dois anos, mais de 200 espaços de grupos de trabalho foram criados pelos usuários; mais de 67 mil documentos compartilhados e 800 discussões abertas nos ambientes. Também houve redução na circulação de papéis na empresa por conta da visualização de processos online; e a concentração e o compartilhamento de documentos em um único lugar vêm agilizando os trâmites burocráticos e o trabalho colaborativo.

A entrevistada mencionou ainda como benefícios: a otimização do tempo (marcação de agenda/salas de reunião por meio de um calendário); o acesso remoto, fora do local de trabalho; a realização de fóruns de melhores práticas e de enciclopédia corporativa (em que 
são catalogadas as melhores práticas); o mapeamento de todas as competências do corpo funcional, facilitando a composição de equipes de projetos na instituição; e a geração de relatórios a partir de discussões, contribuições e comentários.

Com a perda de autonomia e mudança na estrutura hierárquica do setor de GC, os recursos destinados ao projeto tornaram-se escassos, resultando na redução de profissionais e investimentos.

\subsubsection{Gestão do Conhecimento na Organização C}

A organização $C$ é uma prestadora de serviços sem fins lucrativos e está situada no Rio de Janeiro. Seu quadro de pessoal é composto por 110 funcionários e atua no país e no cenário internacional. A Gerência Executiva de GC se reporta ao secretário geral (que desempenha papel semelhante ao de um CEO) e foi criada em 2014, após a reformulação do planejamento estratégico e das metas corporativas no longo prazo. A principal finalidade da Gerência Executiva foi reorganizar as práticas de GC existentes e realizar novas propostas alinhadas ao negócio da organização.

Esta Gerência Executiva de GC é composta por uma equipe multifuncional com 15 profissionais envolvidos das seguintes áreas: Gerência de Tecnologia e Inovação (2), Gerência de Certificação (4), Gerência de Normalização (5), Centro de Informação e Documentação (3) e uma profissional especialista em Gestão de GC, que foi entrevistada para este trabalho. Ela é graduada em Psicologia e possui duas pós-graduações: Administração de Empresas, e Gestão do Conhecimento e Inteligência Empresarial; além de possuir experiência profissional em GC para desempenhar a função de gerente de Projeto de GC.

Entre as principais atribuições dessa facilitadora no processo de implantação de GC destacam-se a responsabilidade de apoiar a criação de um ambiente que incentive o engajamento das áreas técnicas e administrativas; facilitar a disseminação de uma cultura de colaboração; definir e manter políticas e ações que capturem e disseminem o conhecimento; apoiar o desenvolvimento da ferramenta de colaboração junto à área de Tecnologia da Informação; definir e acompanhar métricas da ferramenta de colaboração; estabelecer a missão e governança da área de GC; e organizar fóruns de debates.

As diretrizes estratégicas que serviram como inputs relevantes para a estruturação desse projeto foram: transformar o conhecimento organizacional em valor reconhecido pelos stakeholders e, consequentemente, tornar a organização mais atrativa; maximizar resultados acelerando a taxa de aprendizagem e a retenção dos ativos internos e externos de conhecimento; alinhar os projetos de GC aos objetivos estratégicos de médio e longo prazos da organização, potencializando-os e permitindo aferir resultados diretos e indiretos, tangíveis e intangíveis; desenvolver projetos por áreas ou processos que possam ter impacto mais relevante e abrangente na organização, priorizando-os em função da melhor relação custo e benefício, sob as óticas operacional, financeira e de impacto nas estratégias futuras.

Para um diagnóstico inicial do nível de maturidade de GC, a gerente de Projeto GC conduziu entrevistas com os principais executivos e seus gestores diretos. $O$ resultado gerou um mapeamento detalhado do conhecimento tácito e um levantamento dos conhecimentos críticos das práticas de GC na organização.

A organização $C$ possui uma plataforma de acervo digital composta por documentos corporativos e uma biblioteca com uma diversidade de títulos, artigos, livros etc. Para a entrevistada, o principal desafio é a reformatação da plataforma, transformando-a em um Portal do Conhecimento disponível no site institucional e aberta aos associados. Com a ajuda de um programa de incentivos, liderado pela área de Comunicação Interna, a Instituição pretende captar o arquivamento de documentos corporativos.

Perspectivas em Gestão \& Conhecimento, João Pessoa, v. 7, Número Especial, p. 145-159, mar. 2017. 
Como o projeto de GC estava em fase inicial, na data desta entrevista, faltavam ainda identificar quais seriam as plataformas tecnológicas a serem utilizadas, realizar workshops internos para disseminação do tema e implantar uma cultura de GC. A Organização $C$ ainda não havia chegado, também, à fase de construção dos indicadores e, para isso, pretendia contar com recursos tecnológicos no acompanhamento das métricas.

\subsubsection{Estudo Comparativo das Organizações A, B e C}

A primeira questão sobre a qual os entrevistados concordam é o fato de que os processos de GC precisam estar sintonizados com os objetivos estratégicos da organização, a missão, a visão e valores para o alcance dos resultados esperados. Segundo eles, um ambiente interno favorável à colaboração, no qual a confiança é um valor para os colaboradores, propicia a adoção de práticas de GC. Partindo dessa premissa, qualquer que seja a estratégia definida em um processo de implantação de GC, a cultura organizacional merece especial atenção, pois possibilita ou não o engajamento dos colaboradores no processo.

$O$ resultado das entrevistas mostrou também o nível de maturidade das empresas. A GC na organização A não consegue alcançar toda a rede de colaboradores na disseminação do conhecimento. Na verdade, faz o movimento contrário: busca informações e conhecimentos pertinentes para elaboração e gerenciamento de projetos na área em que está alocada: Gestão de Projetos e Investimentos. Talvez, isso seja um dos motivos da falta de confiança no ambiente interno, pois o conhecimento não é disseminado para todos.

A GC na organização $B$, apesar de possuir um sólido portal de compartilhamento - a Intranet -, ainda não conseguiu envolver todos os colaboradores no uso das inúmeras funcionalidades do portal. Além disso, não dispõe mais de recursos para atualização da ferramenta, correndo o risco de ficar defasada.

A organização $C$ está iniciando um projeto integrador de GC e, apesar de já ter definido o escopo do trabalho a ser desenvolvido por meio de um planejamento de ações pautado em um diagnóstico inicial, carece de suporte das áreas de Tecnologia da Informação e de uma área de Comunicação Interna alinhada aos preceitos de GC para ajudar na disseminação da cultura de GC, por meio de ações de endomarketing e workshops.

Esta análise também mostrou que não existe um padrão na formação dos profissionais envolvidos na gestão do conhecimento, mas algumas características do gestor podem contribuir para o sucesso do trabalho: bom relacionamento interpessoal para criar pontes com várias áreas da organização, experiência em gestão de projetos, habilidades em comunicação e em tecnologia da informação, por exemplo, podem ser um diferencial para o profissional.

A plataforma SharePoint é utilizada nas empresas A e B. No entanto, a organização B desponta na frente por ter investido no projeto de customização das funcionalidades. $A$ organização B, inclusive, é benchmarking para implantação de um portal de GC nas organizações A e C. Um ponto fraco na GC nessas empresas é a falta de indicadores e métricas para mensurar qualitativamente a participação dos colaboradores em plataformas colaborativas. Nas empresas A e B são realizadas apenas as mensurações quantitativas, sem aprofundamento das análises qualitativas das interações.

Sem um patrocinador com autonomia, inclusive financeira, as ações de GC acabam se restringindo a um setor específico, de escopo e abrangência limitados. $O$ patrocinador enxerga na implantação da GC vantagens para a "organização que aprende". A empresa B, no início, contava com o apoio da Diretoria de Inovação, mas atualmente está relegada a segundo plano devido à mudança de objetivos estratégicos e à nova política de redução de custos. A empresa C, por outro lado, conta com o patrocínio da alta administração e a formação de um grupo multifuncional que fortalece as ações e a mudança de cultura interna.

Perspectivas em Gestão \& Conhecimento, João Pessoa, v. 7, Número Especial, p. 145-159, mar. 2017. 
Três áreas-chave nas organizações são citadas quando o assunto é Gestão do Conhecimento: Recursos Humanos, Tecnologia da Informação e Comunicação. Elas facilitam processos e projetos nas empresas, impulsionando a Gestão do Conhecimento. Pessoas, tecnologia e comunicação formam uma tríade que retroalimenta a dinâmica de criar, capturar, disseminar e avaliar conhecimentos, possibilitando a inovação de produtos e serviços.

Nas empresas A e C, a área de Recursos Humanos exerce função preponderante na implantação de GC, enquanto a Comunicação é a responsável pelas ações na organização $B$.

Nesse contexto, as áreas de Tecnologia da Informação, Recursos Humanos, Comunicação e Projetos são preponderantes na promoção da cultura alinhada aos princípios de GC, oferecendo suporte necessário para que as ações e práticas tornem-se rotineiras pelos funcionários.

\subsubsection{Práticas de Gestão do Conhecimento}

Para implantar uma gestão eficaz do conhecimento são necessárias algumas práticas cotidianas que colaborem no esforço de integrar os processos de uma empresa e promovam o aprendizado coletivo. Durante a realização desta pesquisa, várias práticas organizacionais foram citadas pelos entrevistados, conforme exemplos descritos abaixo e classificados de acordo com os processos de conhecimento: organizar, criar, compartilhar e proteger.

- Oficinas de aprendizagem - é uma metodologia que compreende o trabalho em equipe para a construção coletiva e/ou solução de problemas. Por meio de dinâmicas de grupo, as oficinas proporcionam um aprendizado integrado e crítico, baseado na troca de experiências e na problematização de realidades. Estão relacionadas aos processos do conhecimento - organizar, compartilhar e criar.

- Design Thinking - é uma metodologia de pensamento crítico e criação que estimula o surgimento ou a melhoria de novos produtos, projetos ou serviços, por meio da organização de informações e ideias, auxiliando a tomada de decisão e a aquisição de novos conhecimentos. Está relacionado aos processos do conhecimento - organizar e criar.

- Mapeamento de processos - é uma ferramenta gerencial e de comunicação que determina a melhoria dos processos ou a implantação de uma nova cultura, com objetivo de melhorar a satisfação do cliente e o desempenho do negócio. Está relacionado aos processos do conhecimento - organizar, proteger e criar.

- Sistema de gestão de documentos - é um sistema que organiza e controla os documentos, de modo que as pessoas consigam acessá-las de forma segura. Está relacionado aos processos do conhecimento - organizar e proteger.

- Registro de lições aprendidas - é uma forma de documentar as experiências adquiridas por meio de resolução de problemas reais, que são registrados, documentados e divulgados em ambiente comum, a fim de evitar que os mesmos problemas apareçam novamente. Está relacionado aos processos do conhecimento - organizar, criar, compartilhar e proteger.

- Mentoria - é um processo de aprendizado e desenvolvimento profissional que uma pessoa com mais experiência ajuda, apoia e transmite o seu conhecimento para outra 
pessoa menos experiente, por meio de conversas ou vivências no ambiente de trabalho. Está relacionada aos processos do conhecimento - compartilhar e proteger.

- Comunidades de prática - são equipes ou grupos de pessoas que compartilham seus conhecimentos, de forma criativa, em torno de um assunto, para transformar ou melhorar uma situação atual. Estão relacionadas aos processos do conhecimento compartilhar e criar.

- Mapa mental - é um diagrama estruturado para a gestão de informações, de conhecimento e de capital intelectual que facilita a compreensão e solução de problemas. Está relacionado aos processos do conhecimento - organizar, compartilhar e proteger.

- Coaching - é uma metodologia que utiliza técnicas e ferramentas visando o aprimoramento de competências pessoal ou profissional, por meio de sessões estruturadas e/ou reuniões a fim de ajudar e guiar uma pessoa em seu desenvolvimento. Está relacionado aos processos do conhecimento - criar e proteger.

- Aprender trabalhando ou "on the job" - é uma prática muito utilizada nas empresas, onde as pessoas aprendem com outras pessoas, no dia a dia, enquanto desempenham suas atividades. Está relacionado ao processo do conhecimento - compartilhar.

Figura 2 - Práticas de Gestão do Conhecimento

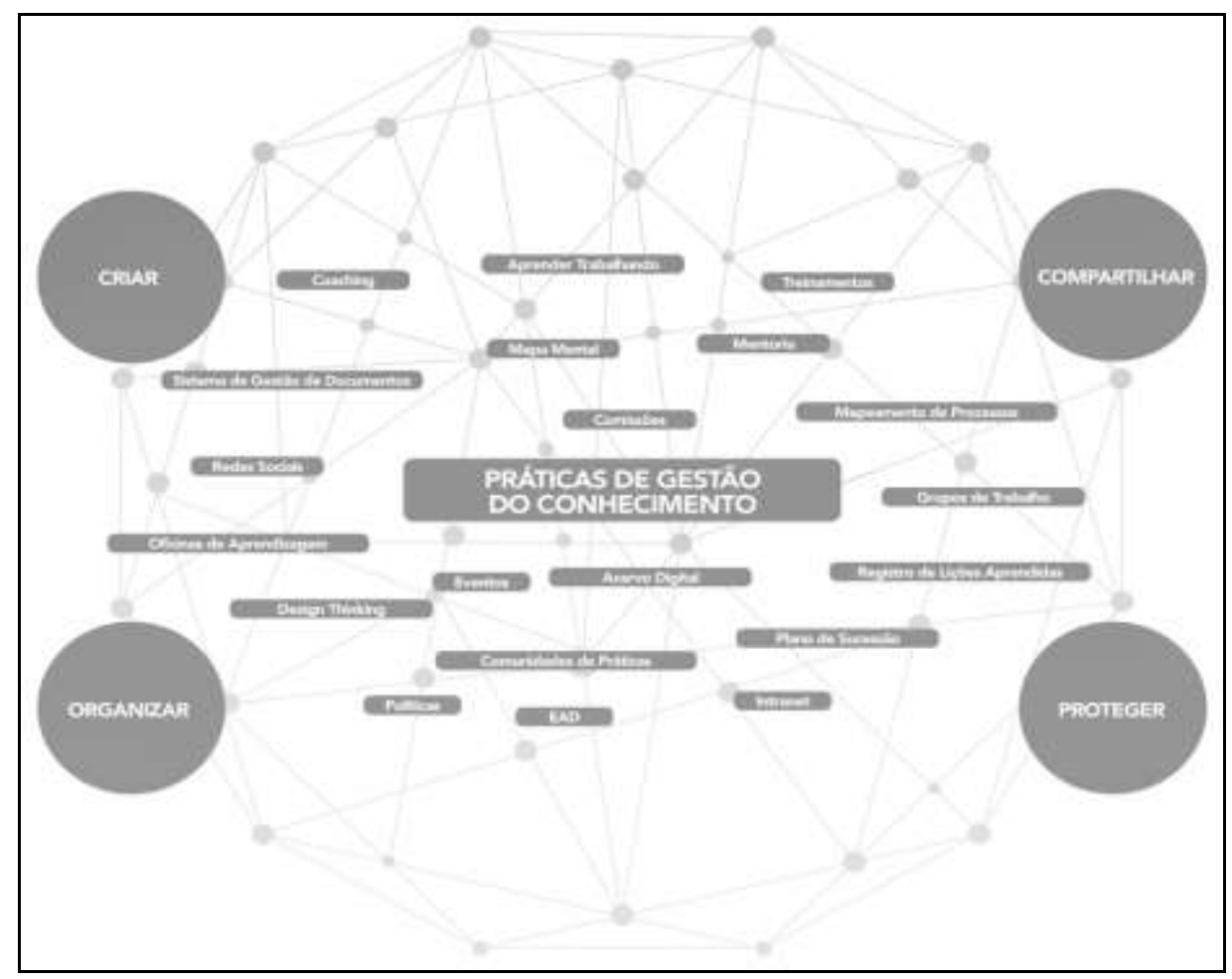

Fonte: Autoria própria 
A figura mostra várias práticas de GC que se interconectam e que contribuem para o desenvolvimento da empresa por meio da aprendizagem (Ensino a Distância-EAD, Lições Aprendidas, Aprender trabalhando), da informação (Políticas, Intranet, Redes Sociais etc), do treinamento (Coaching, Mentoring), do trabalho colaborativo (Comunidades de Práticas), da utilização de técnicas criativas (Mapa mental, Design Thinking) de eventos, entre outras.

\section{CONSIDERAÇÕES FINAIS}

O presente trabalho propôs-se a investigar o processo de Gestão do Conhecimento nas organizações hipertexto. Para isso, foram realizadas entrevistas semiestruturadas com profissionais de três empresas do setor industrial com essa configuração. A análise preliminar resultou na identificação das áreas-chave que impulsionam a GC nas organizações - Tecnologia da Informação, Recursos Humanos, Comunicação e Projetos - e no mapeamento das práticas de Gestão do Conhecimento.

A fim de continuar o debate sobre os resultados desta pesquisa as autoras propõem a criação de um site na plataforma Wix.com ${ }^{3}$, para formar uma Rede Colaborativa de Gestão do Conhecimento, denominada Colabore. Esta seria destinada a todos os gestores do conhecimento, ou seja, qualquer pessoa que esteja vinculada a uma organização e deseja trocar informações, impressões e conhecimentos de processos com outras pessoas. A ideia parte do princípio de que cada pessoa é responsável por seu próprio aprendizado, ou seja, atuando individualmente como Personal Knowledge Management (PKM), e que todos, não somente os especialistas da área, possuem conhecimento a partilhar e contribuir para o aprimoramento das práticas de gestão do conhecimento nas organizações.

A escolha do nome Colabore tem a ver com seu próprio significado na língua portuguesa, pois advém do verbo colaborar": "trabalhar com uma ou mais pessoas em uma obra, cooperar, participar", que é condição primária para se promover a espiral do conhecimento nas organizações. A utilização do modo imperativo - Colabore - funciona como um convite à participação. Inicialmente, a plataforma abordaria temas relevantes para a GC contidos neste estudo, como a necessidade de um patrocinador, de engajamento dos colaboradores, a importância da cultura organizacional, e a integração das áreas consideradas propulsoras da GC, em forma de artigos, posts e discussões em fóruns temáticos de acordo com as funcionalidades: Blog, Acervo, Fórum Colabore, Agenda, Oportunidades et.

No entanto, para desenvolver uma plataforma transmídia sobre GC são necessários aprimoramentos no modelo de site responsivo, ou seja, adaptativo a diferentes contextos de uso e em qualquer dispositivo: mobile, tablet, smartphone, desktop. Outro desafio para o Colabore é a produção de conteúdo instigante, atual e em tempo real, mantendo os internautas, que trabalham em organizações, conectados e em rede. A utilização da ferramenta Google Analytics, que analisa dados digitais e monitora o tráfego em sites, poderia contribuir na identificação de perfil dos participantes, seus interesses e comportamentos.

Para o aprofundamento da discussão apresentada neste artigo, a participação de representantes de organizações de outros setores da Economia, como o Comércio e Terceiro Setor, em futuras entrevistas utilizando a mesma metodologia, aumentaria o grau de complexidade, tendo em vista o modelo comparativo dos processos de GC e o nível de maturidade dessas empresas.

\footnotetext{
${ }^{3}$ A plataforma online WIX.com permite aos usuários, sem habilidades em programação, criar seus próprios sites em HTML e Mobile, por meio de ferramentas e templates de simples customização e adição de aplicativos de terceiros, como soluções e-Commerce, chats online, entre outros, para divulgação de uma ideia ou marca na internet.
}

${ }^{4}$ COLABORAR. In: DICIO: dicionário online de português. Disponível em: http://www.dicio.com.br/colaborar/. 
Por fim, este trabalho buscou contribuir com o estudo da construção da Gestão do Conhecimento nas organizações e com a identificação de processos e redes de aprendizagem, que fazem as empresas atuarem de forma colaborativa.

\section{REFERÊNCIAS}

ALBERS, James A. A practical approach to implementing knowledge management. Journal of Knowledge to Implementing Knowledge Management, v. 10, n. 1, p. 15-20, 2009.

CARVALHO, Fábio. Gestão do conhecimento. São Paulo: Ed. Pearson, 2012.

CAVALCANTI, Marcos. Anotações de aula da turma MBKM26. Rio de Janeiro: Crie/Coppe/UFRJ, 2014.

COSTA, Katia; SCOTT, Patrícia; VALENTIM, Patrícia. Gestão do conhecimento nas organizações: uma aprendizagem em rede colaborativa. 2015. 43f. Monografia (Especialização em Gestão do Conhecimento e Inteligência Empresarial) - Universidade Federal do Rio de Janeiro, Rio de Janeiro, 2015.

BANCO NACIONAL DE DESENVOLVIMENTO ECONÔMICO E SOCIAL (Brasil). Porte de empresa. Rio de Janeiro, [2011]. Disponível em: http://www.bndes.gov.br/SiteBNDES/bndes/bndes pt/Institucional/Apoio Financeiro/porte.h tml. Acesso em: 7 ago. 2015.

CHOO, Chun Wei. A organização do conhecimento. São Paulo: Ed. Senac São Paulo, 2003. COLABORAR. In: DICIO: dicionário online de português. Disponível em: http://www.dicio.com.br/colaborar/. Acesso em: 15 set. 2015.

EDVINSSON, Leif; MALONE, Michael S. Capital intelectual: descobrindo o valor real de sua empresa pela identificação de seus valores internos. São Paulo: Makron Books, 1998.

GOMES, Elisabeth; BRAGA, Fabiane. Inteligência competitiva: como transformar informação em um negócio lucrativo. Rio de Janeiro: Campus, 2001.

JUDY, Stephanie; HAMMOND Susan. An introduction to appreciative inquiry. [S.I.]: Silva Forest Foundation, Feb. 2006. Disponível em:

http://silvafor.org/assets/silva/PDF/Appreciativelnquirylntro03-09.pdf. Acesso em: 7 ago. 2015.

KAPLAN, Robert S.; NORTON, David P. Estratégia em ação: balanced scorecard. Rio de Janeiro: Elsevier, 1997.

KATZ, Ralph et al. Organizations. In: DORF, Richard C. (Ed.). The technology management handbook. Boca Raton: CRC Press, 2000. cap. 7.

THE KNOW Network. Disponível em: http://www.knowledgebusiness.com/knowledgebusiness/Screens/MakeSurvey.aspx?siteld=1 \&menultemld=4. Acesso em: 5 ago. 2015. 
NONAKA, I.; TAKEUCHI, H. A criação de conhecimento na empresa. Rio de Janeiro: Elsevier, 1997.

NORTH, Klaus. Gestão do conhecimento: um guia prático rumo à empresa inteligente. Rio de Janeiro: Qualimark, 2010.

OLIVEIRA, Carla. Que são o processo gerencial middle-up-down e a organização hipertexto. Disponível em: http://imasters.com.br/gestao/o-que-sao-o-processo-gerencial-middle-updown-e-a-organizacao-hipertexto/. Acesso em: 4 ago. 2015.

ROSSETTI, Adroaldo Guimarães; MORALES, Aran Bey Tcholakian. O papel da tecnologia da informação na gestão do conhecimento. Ciência da Informação, Brasília, v. 36, n. 1, p. 124135, jan/abr.2007.

SENGE, Peter M. A quinta disciplina: arte e prática da organização que aprende. Rio de Janeiro: Best Seller, 2008.

STEWART, Thomas A. Capital Intelectual: a nova vantagem competitiva das empresas. Rio de Janeiro: Campus, 1998.

SVEIBY, Karl Erik. A nova riqueza das organizações: gerenciando e avaliando patrimônios de conhecimento. Rio de Janeiro: Campus, 1998.

TUOMI, likka. From periphery to center: emerging research topics on knowledge society. Technology Review, Helsinki, v.16, p. 1-63, ago. 2001.

Artigo recebido em 16/07/2016 e aceito para publicação em 14/03/2017 